\title{
How bountiful is the ocean? Participatory valuation of human-nature relationships in Yaeyama Islands, Okinawa, Japan
}

\author{
Aoi Sugimoto $^{1}\left(\mathbb{D} \cdot\right.$ Hiroaki Sugino $^{2} \cdot$ Juri Hori $^{3}$
}

Received: 25 November 2020 / Accepted: 17 June 2021 / Published online: 10 July 2021

(c) The Author(s) 2021

\begin{abstract}
Valuations of nature are vital for effective conservation planning, and discussions are underway globally on improving the valuation process. Plural valuations of human-nature relationships are the key for better, more inclusive decision-making, which is demonstrated in this research using a case study on human-ocean relationships on Ishigaki Island, a part of the Yaeyama archipelago, Japan. We applied a network analysis to text data obtained from answers on questionnaires with openended questions to quantify the importance of values with respect to the pluralities among local people. Therefore, five core elements encompassing the values of the human-ocean relationships on Ishigaki Island were proposed as follows: "Livelihood," "Attachment and inspiration," "Local marine culture," "Respect and fear for nature," and "Anthropocene environmental problems." The "Anthropocene environmental problems" element included social and environmental problems caused by various human activities including excessive tourism development, and the data collected through tourism market value analysis implied that past ecosystem service assessments may have over-valued or even triggered this issue. The "Respect and fear for nature" element was found to be important as a potentially unique value in these regions, but this is currently understudied within the literature related to ecosystem services and nature's contributions to people. This study is among the first works to extract and visualize place-based human-ocean relations in an Asian country. We hope that our methods and findings will be applied to other areas, especially to the local communities of understudied countries and regions, to drive the transformative change of coral reef governance in the Anthropocene.
\end{abstract}

Keywords Nature's contributions to people $\cdot$ Ecosystem service $\cdot$ Human-ocean relationship $\cdot$ Marine conservation · Qualitative and quantitative content analysis

\section{Introduction}

\section{Valuation of human-nature relations: ecosystem services and nature's contributions to people}

Human-nature relationships have remained one of the most renowned topics of inquiries since ancient times. In the context of environmental sciences and policy making, global society has recently become engaged in the valuation and assessment of nature through the Millennium Ecosystem Assessment (MA 2005), followed by The Economics of Ecosystems and Biodiversity (TEEB 2010), the Japan Satoyama Satoumi Assessment (JSSA) (2010), and the UK National Ecosystem Assessment (UK NEA) (2011, 2014). The Intergovernmental Science-Policy Platform on Biodiversity and Ecosystem Services (IPBES) $(2018,2019)$ introduced a new concept called nature's contributions to people (NCP), defined as all 
the contributions, both positive and negative, of living nature (diversity of organisms, ecosystems, and their associated ecological and evolutionary processes) to the people's quality of life (Díaz 2018; IPBES 2018, 2019; Pascual 2017) in the latest Global Assessment. The concept of NCP, as the core of the IPBES framework, is intended to broaden the scope of the ecosystem services (ES) framework (Diaz et al. 2018; Kenter 2018; Pascual et al. 2017). The development of this concept was mainly prompted by the need for value pluralism. In particular, the individual monetary valuation of ES largely failed to engage diverse perspectives from scientific disciplines, conservation practitioners as well as those of local and indigenous communities (Díaz et al. 2018; Pascual et al. 2017). The initial skepticism toward this framework turned into active opposition, often based on the perceived risks of the commodification of nature (Díaz et al. 2018; Gómez-Baggethun et al. 2010; Martin-Ortega et al. 2019). The need for value pluralism, both in terms of the incorporation of the diversity of knowledge and the representation of various worldviews, interests, and values, requires a transition from the IPBES process to the use of the NCP framework (Díaz et al. 2018). Another motive behind the development of NCP was the limitations of the cultural ES (CES) framework. Specifically, CES, defined as the non-material benefits people obtain from ecosystems in the MA (2005), is a sub-category in line with supporting, regulating, and provisioning services. This category was particularly criticized by social sciences and humanities scholars because it had been side-lined within the ES monetary valuation framework because of its intangible, (inter-) subjective, and incommensurable characteristics generated by the complex interrelation between people and nature (Chan 2012a; Chan et al. 2012b; Daniel 2012; Fish et al. 2016; Ishihara 2018; Milcu 2013). Recently introduced frameworks, such as NCP, have attempted to address the limitations of the previous CES concept by acknowledging the central and pervasive role that culture plays in framing human-nature relationships among diverse worldviews (Chan 2016; Díaz et al. 2018; Fish et al. 2016; Pascual et al. 2017; Pereira et al. 2020). The NCP framework has context-specific perspectives for more meaningful valuations/assessments of nature, in contrast to a universally applicable classification scheme-such as that proposed in the previous ES framework and that derived from a generalized perspective of NCP - as the latter approach may be inappropriate because of an incommensurability of values and the resistance against universal perspectives on human-nature relations (Díaz et al. 2018).

\section{Past valuations/assessments of CES and relevant concepts}

Even though monetary valuations, which are most often conducted in conjunction with recreation and tourism industries, have long been centered on CES assessments (Chan et al. 2012b; Martin et al. 2016; Milcu et al. 2013; Pert 2015), there is also a rich accumulation of literature on more intangible, non-monetary CES assessments, such as those focused on aesthetic and spiritual values (e.g., Cooper et al. 2016; Ishii 2010) or sense of place (e.g., Urquhart and Acott 2014). Recently, some authors have proposed a wider exploration of human-nature relations that are not restricted to the previous CES framework through pace-based investigations in local and indigenous communities with strong cultural ties. For instance, Pascua et al. (2017) described a case study of a Hawaiian community, in which the following four main categories of human-nature relations were used: 'Ike (knowledge), Mana (spiritual landscapes), Pilina Kanaka (social interactions), and Ola Mau (physical and mental wellbeing). Another instance, again based on a Hawaiian case study, was presented by Gould et al. (2019), proposing five longstanding Hawaiian values that embody notions of appropriate relationships, including human-ecosystem relationships: pono ( righteousness, balance), ho'omana ( creating spirituality), mālama ( care), kuleana ( right, responsibility), and aloha ( love, connection). Past works have also dealt with relevant concepts to CES but have applied other terms to better capture the intangible and (inter-) subjective characteristics of human-nature relations. Notably, "social values" and "shared values" have been included as a distinguishable value category by the UK NEA-Follow on (National Ecosystem Assessment) (2014), along with theoretical investigations (Kenter 2015, 2016; Gould et al. 2019). Relational values, defined as preferences, principles, and virtues associated with relationships, both interpersonal and as articulated by policies and social norms (Chan et al. 2016; Himes and Muraca 2018), have also been proposed to obtain a better understanding of human-nature relations. The aim of introducing these concepts is to overcome the dichotomy between intrinsic and instrumental values, again for the sake of plural valuations/assessments of nature that are more inclusive of diverse worldviews and knowledge (Chan et al. 2016; Gould et al. 2019).

\section{Objective of this study}

Global society is now aware of the importance of plural valuations/assessments of context-specific, place-based values that people hold toward nature as the vital starting point for effective conservation. Thus, this study aims to enrich this school of knowledge in relation to both geographical and methodological aspects. Geographically, we focus on a case study of Ishigaki Island, Japan, which is located in the most southwesterly part of the country as a part of Yaeyama archipelago with a subtropical climate and coral reef ecosystems. It has been recognized that Asian countries have been poorly studied with regard to human-nature relations in the NCP/ES literature (Christie et al. 2019; Martin et al. 
2016; Milcu et al. 2013; IPBES 2018 but a few exceptions such as Chakraborty and Gasparatos 2019; Lau et al. 2019). Yet importantly, this region contains extremely rich marine ecosystems and has experienced rapid environmental degradation, coinciding with economic growth (IPBES 2018). Furthermore, coral reefs are one of the most threatened ecosystems, due to anthropogenic factors including the climate change (e.g., Hughes et al. 2003, 2017; IPBES 2019). This is undoubtedly the case in Japan too, where the degradation of coral reefs has mainly been caused by multiple bleaching events and land-based run-off due to intensive coastal and agricultural development (Hongo and Yamano 2013; Harii et al. 2014; Yamano et al. 2015). A few previous works have documented the ES of coral reefs through monetary valuations (MOE (Ministry of the Environment) Japan 2010; Sato et al. 2020); however, the plural valuation of coral reef ES has been scarce thus far in Asian countries, as aforementioned. Given the accelerated change of coral reef ecosystems, it is urgently needed to offer plural valuation of coral reefs to inform marine conservation planning to ensure appropriate measures are taken to protect these ecosystems.

This study used a methodological approach and applied a mixed method of qualitative content analysis and quantitative network analysis on text data obtained by questionnaires with open-ended questions. This approach allowed the respondents to express their own relationships with nature in diverse ways, removing the bias associated with frameworks and perspectives set by the "experts" such as scientists and policymakers (Gould 2015). This method well fits the core motivations for new plural valuations of nature that is to include "non-Western" views held by local communities. For the qualitative assessment, we applied qualitative content analysis, such as the formation of qualitative categories (Lazarsfeld and Barton 1951), which is a suitable approach for gaining insight into text data through a comprehensive search of the entire dataset (Saporta and Sebeok 1959). In addition, this study applied network analysis as a quantitative content analysis method for the visualization of human-nature relations. Social network analysis has been extensively utilized to examine the relationship between extracted factors and objects related to various types of social capital and natural resource governance (e.g., Barnes et al. 2016; Bodin and Crona 2009; Crona and Bodin 2006; Cvitanovic et al. 2017; Österblom et al. 2017; Packer and Bailey 2020) in the context of environmental and sustainability sciences. However, the network analysis of text data has been utilized outside those disciplines, such as in medical, nursing, and educational applications, as one of the methods for content analysis (Danowski 1993; Osgood 1959). Given the proven strength of quantitative, computerbased text content analysis in the collection of valuable information from text data (Feldman and Sanger 2007), we considered that it would be beneficial to apply this approach in the present plural valuation of human-nature relations.

\section{Methods}

\section{Case study site}

\section{General description}

Our case study site, Ishigaki Island, Okinawa prefecture, is located in the southwestern part of Japan as one part of the Yaeyama archipelago (Fig. 1), with a population of 47,564 (Ministry of Internal Affairs and Communication 2015). We selected this site because although this region has been identified as a high-priority area for marine conservation in Japan with the largest coral reef "Sekisei lagoon" in the country, it is experiencing severe ecosystem threats such as massive bleaching (MOE Japan 2010; Kayanne et al. 2017; Sato et al. 2020). In addition, the second reason for selecting this site was related to the unique cultural context of this island within the country. Prior to the establishment of Okinawa prefecture by Japan's Meiji government (1868-1912), Okinawa was not a part of Japan, but known as the Kingdom of Ryukyu, which existed from 1429 to 1879. After WWII, Okinawa was colonized by the U.S. until 1972. Ever since it has been re-integrated as a part of Japan, and the Okinawa prefectural government has been trying to develop its economy by promoting tourism and advertising Okinawa as a "subtropical, exotic paradise island" to Japanese tourists (Tada 2004, 2008). Thus, even inside the country, Okinawa has a unique socio-ecological setting, which makes it suitable for exploring ways to incorporate context-specific human-ocean relations into conservation planning. This study will offer the human-ocean relationship of Yaeyama Islands, which can be represented by the case study of Ishigaki Island.

\section{Human-ocean relations on the island}

People on the Okinawan Islands, including Ishigaki, use their village lagoons for subsistence fishing (when not farming) and during their leisure hours. Such "half farmers-half fishers" have traditionally owned and managed these village lagoons as common pool resources (e.g., Kumamoto 1995; Tabeta 1990). In addition to traditional subsistence fishing activities, fishing as a full-time profession was introduced by immigrants from the other Okinawan Islands after WWII (Tabeta 1990). Besides subsistence and commercial uses, Okinawan coastal communities attach spiritual and religious values to the ocean. On the Okinawan Islands, there is a belief in the existence of a "paradise" over the ocean called "Niraikanai," where one should never reach for anything 


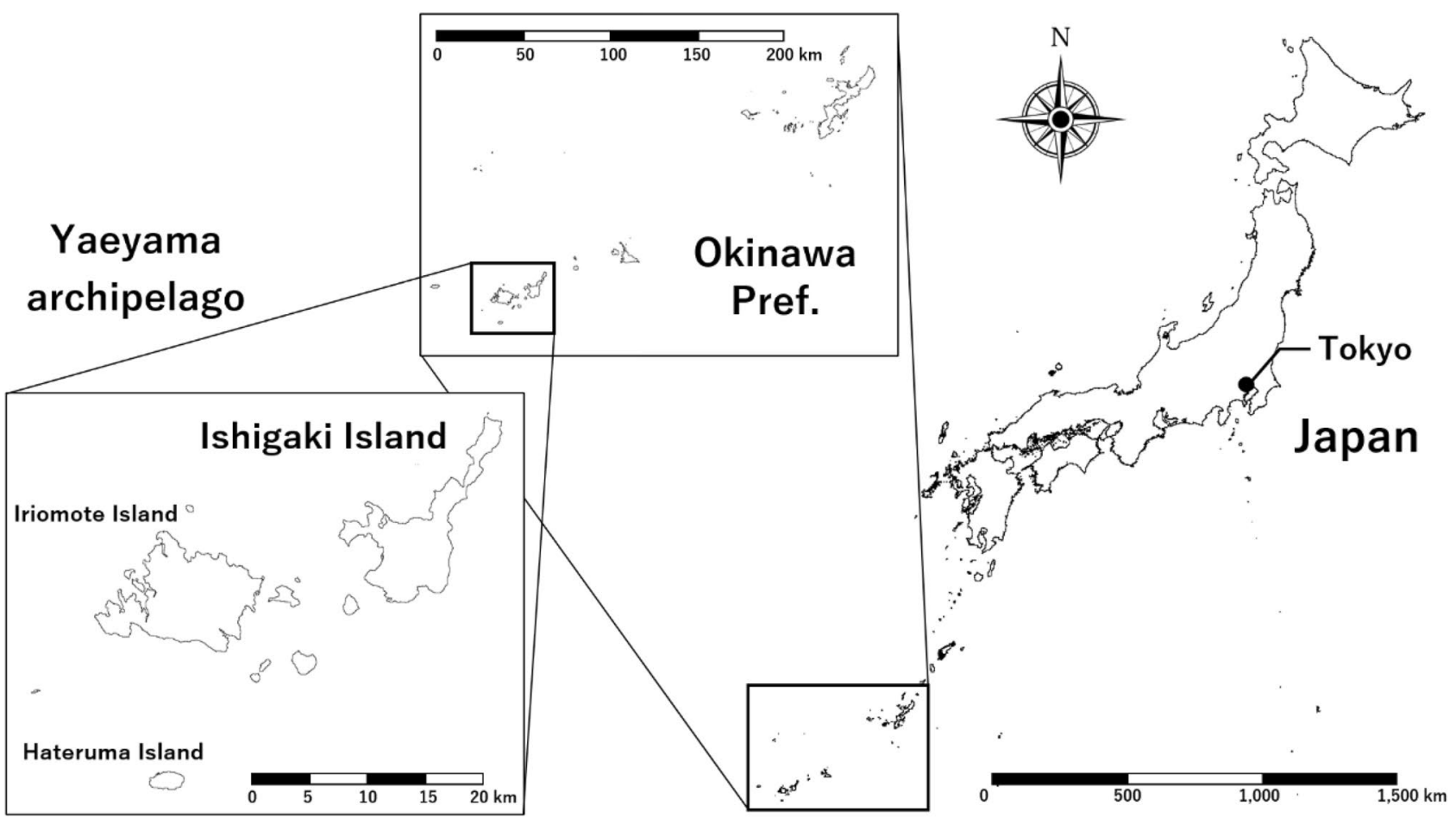

Fig. 1 Location of the study site, Ishigaki Island (part of Yaeyama archipelago)

thanks to the bountiful gifts available to the community, such as schools of fish, agricultural products, precious driftage, visitors who bring new techniques and cultures, and various other blessings (Nakamatsu 1990). Thus, as can be seen from the region's history and customs, the coastal communities on Okinawa consider the common village seas having economic, social, and cultural values (Sugimoto 2016) (also see Photo 1). More recently, particularly since 1980, marine tourism has become an important industry on Ishigaki and the other Okinawan Islands, as mentioned above. According to Ishigaki city (2018), tourism is regarded as a "core industry" and will continue to be promoted. Since 1990, non-Japanese tourists, such as mass groups traveling by cruise ships, have started to visit the island extensively (Tada 2008).

\section{Data collection}

For the plural valuation of human-ocean relations on the island, we engaged with a wide range of local stakeholders through participatory methods. First, we held a series of workshops (hereinafter "Workshop") that took place during 20-29th September, $2019(N=21)$, and invited several types of local stakeholder groups closely related to marine conservation, e.g., local conservation policymakers, environmental activists, fishers, and community organizations. For the identification of "key stakeholders," i.e. those with close connections to marine conservation, we referred to past works (Hori et al. 2017; Makino et al. 2020) as well as ethnographic fieldworks that have been conducted by the first author since 2009. After the identification of the targeted groups, participants were selected in consideration of their willingness to attend the Workshop and availability given the limited period of fieldwork.

First, we held the Workshop for local conservation policymakers and activists $(N=7)$ on September 20th, where we discussed if the Workshop design was easy to understand for the participants of the other groups. We applied the following Workshop design: at first we asked participants two simple questionnaires with open-ended questions (Table 1) pertaining to (1) the resources, places, or phenomena (hereinafter "Resources") that people felt a deep relationship with around the ocean areas on Ishigaki, and (2) the relationships that people held with the resources (hereinafter "Relationships"). The first stage of the Workshop was individual work, which was designed to encourage participants express their own perception without being pressured/biased by the other participants' voices. After this individual work, participants were asked to share their "words" with others. Herein, all the participants knew what everyone wrote down, and had joint conversation on their relationships with Yaeyama ocean. The authors facilitated this conversation, while taking notes that were always visible to all the participants (Photo 2). 


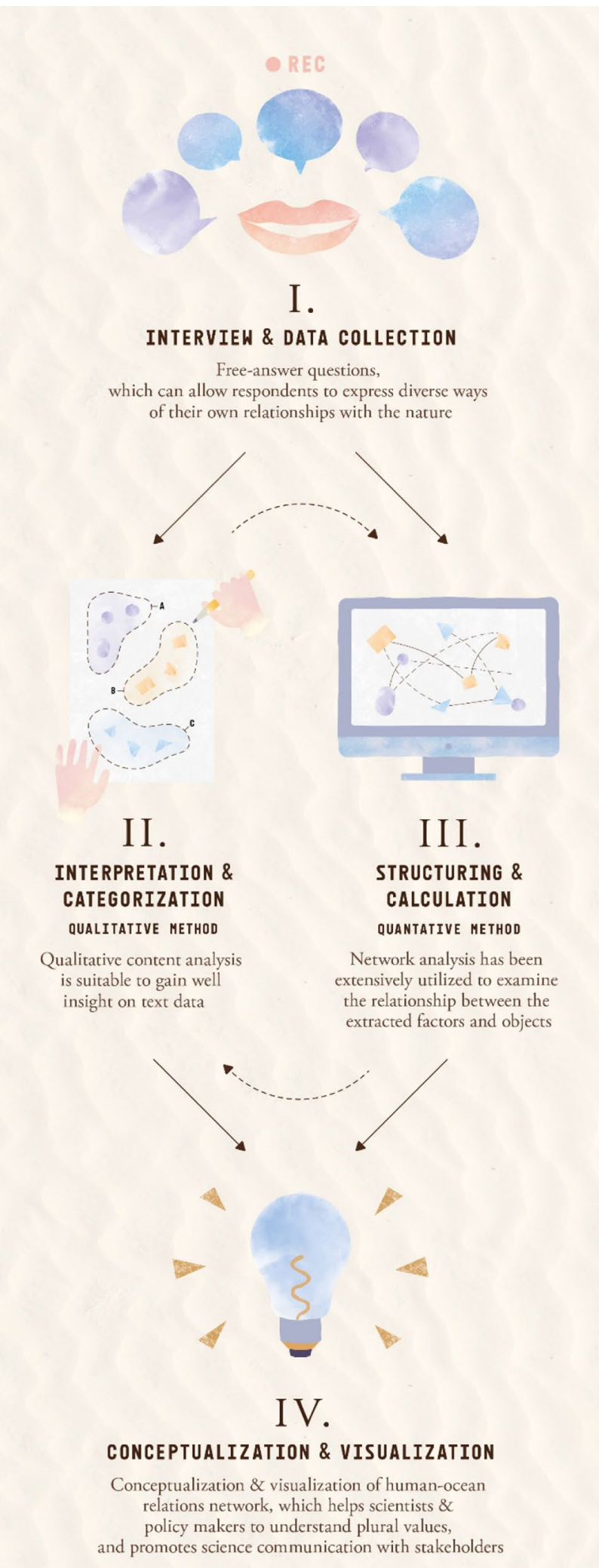

Fig. 2 Infographic showing a summary of the methods used in this work
For each question, we asked the participants to provide answers using a word or a short statement consisting of several words. The reasons for giving this instruction were as follows: first, to make the questions simple and easy to answer for everyone and to reduce the burden on the participants; secondly, to directly obtain coding-ready data that would not require a morphological parsing process; and thirdly, to extract the relationships among the values, factors, and objects related to the ocean surrounding Ishigaki. Ethnographic fieldworks by the first author were substantially utilized to derive the questions used in the participatory valuation of this study, so that they were inclusive and simple enough to understand (Kenter 2018).

By confirming that the questionnaire was well understood by the local people, we then held the following Workshops for fishers on the 21st of September $(N=8)$ and community organizations on the 28 and 29th of September, 2019 $(N=6)$. Considering the mental and physical burden for the participants, every Workshop was finished within $1.5 \mathrm{~h}$ and no participant attended more than one Workshop. We also performed preliminary analysis on these Workshop results which enabled us to see the validity of data collection and analysis methods.

After the series of Workshops and preliminary analysis, we conducted a survey of the citizens of the island (hereinafter "Survey") using the same questionnaire items as those used in the Workshop. To distribute the questionnaire, we firstly selected six communities (the smallest administrative unit) to reflect a balanced representation of the characteristics such as (1) whether the community is traditional or newly established (around a decade or so by the urban development), and (2) whether the community is located in the northern or southern part of the Island, which is thought to be the factor causing the slight "cultural difference" according to local people. The selected communities (out of 2100 in total) and sample sizes (total household numbers) for those were: Ibaruma village (traditional, northern part, $N=170$ ), Kabira village (traditional, northern part, $N=590$ ), Sakieda village (traditional, northern part, $N=100$ ), Shiraho village (traditional, southern part, $N=750$ ), Hamasaki town block 1(newly established, southern part, $N=220$ ), and Hamasaki town block 3 (newly established, southern part, $N=270$ ). Then, we asked the local postal office to post the questionnaire to all the households in the six communities, which were identified by the postal codes. Similar to the Workshops, we paid careful attention that the Survey was easy to understand for the participants. To make sure of this, we asked some of the local people to answer to the survey whom the first author already gained a rapport with through past fieldworks. After several rounds of this "pre-Survey," we made small corrections on the 

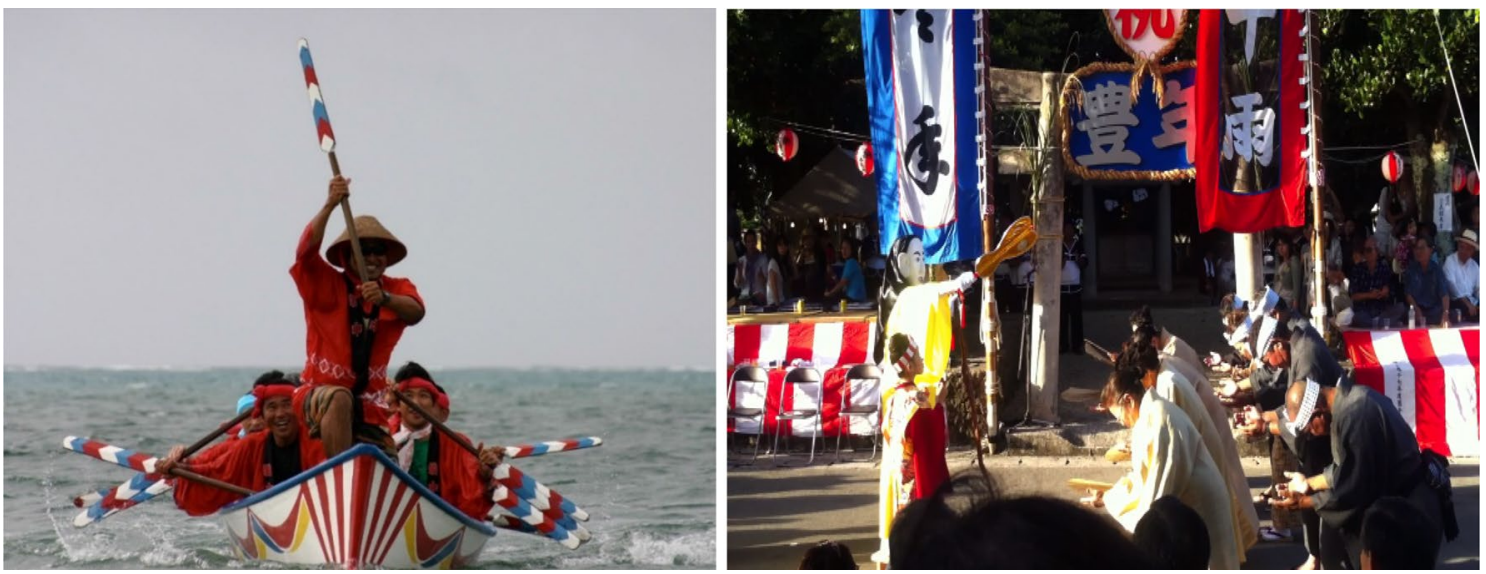

Photo 1 Community festivals, where people pray to the gods that come from Niraikanai for rich harvests from the ocean and farms (photographs taken by first author, August 2011)

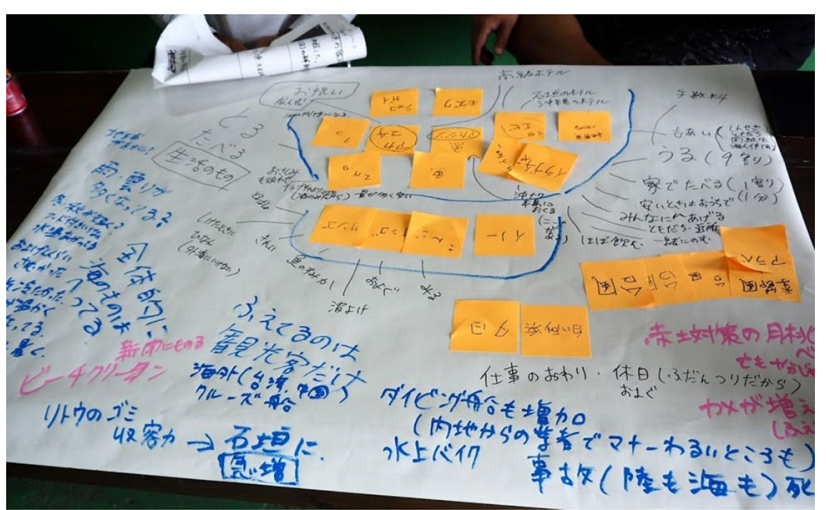

Photo 2 Resources and relationships extracted during the workshop among local fishers (photograph taken by the authors, September 2019)

questionnaire to increase its readability and understandability. In addition, we conducted a semi-structured interview for several locals on the Survey questions to make sure it could capture genuine human-ocean relations. Through this careful design of the data collection, we gained confidence that the approach was being conducted in a sufficiently valid and reliable way. The survey was carried out from March 28 to May 22, 2020. Among all the questionnaires posted, 153 were valid and utilized for the analysis.

\section{Data analysis}

\section{Data coding}

The obtained text data were coded to obtain reasonable categories of words (hereinafter "Categories"). To do this, we applied the coding rules as follows: first and most importantly, we generated the categories in such a manner so as to retain the original meaning of the raw texts as much as possible, but second, given the great diversity of raw texts, we organized similar words into one category. For example, people used similar words such as "coral reef," "reef," "reef edge," "blue coral," and "reef in Ishigaki," for which we generated the category "Coral reef." Another example is that people used similar words such as "gift," "get from neighbors," "send to relatives (or friends)," and "distribute," for which we generated the category "Sharing." This coding was conducted to increase the readability of the results with respect to the contents of the raw texts, and all of the coauthors participated in this process and confirmed that the coding was legitimate. One more item of note is that we noticed that some words were used by participants in the sense of both "Resources" and "Relationships." For instance, one participant used the word "beach" in question (Q) 1 (as Resources) and "walking" in Q2 (as Relationships), while another participant used the word "coral reef" in Q1 and "beach" in Q2. This occurred because some resources and

Table 1 Questionnaire items used in this study

Q1. Please name the resources (e.g., fish, coral reef), places (e.g., beach, reef edge), or phenomenon (e.g., wind, typhoon) with which you are feeling a strong relationship around the ocean of Yaeyama (up to five)

Q2. Please provide the words which describe the relationship between you and the resources, places, or phenomenon you named above (up to three, respectively) 
relationships can be perceived interchangeably by people, which we thought is not unnatural. Therefore, we added "rc" ("resource category") to the respective word if it appeared both as Resources and Relationships to distinguish that the word was raised for both Q1 and Q2.

\section{Network analysis on the coded data and its visualization}

Then, we conducted a network analysis for the coded data to quantify and visualize human-ocean relations using the $\mathrm{R}$ ver. 3.6.1 statistical software (R Core Team 2019). First, a list of edges (pairs of two coded categories) was created by pairing each answer to Q1 with the answers to Q2. While making the list (the so-called edge list or adjacency list), the frequency of the edges was summed up. Based on the edge list and by applying graph theory (Deo 2017), a network of the coded categories was calculated and visualized. After visualizing the data as a network, sub-groups, called subgraphs, in the network were detected by the greedy algorithm of modularity maximization (Newman 2004; Clauset et al. 2004). The greedy algorithm is an agglomerative hierarchical clustering method that repeatedly merges pairs of subgraphs together and chooses the merger for which the resulting modularity (the strength of division of a network into subgraphs) is largest (Chen et al. 2014). According to Fortunato (2010), its advantageous features are that it is less time consuming and burdensome in terms of resources for calculation compared to other subgraph detection algorithms, such as the Girvan-Newman algorithm (Girvan and Newman 2002) and spin glass algorithm (Rerichardt and Bornholdt 2004). However, its detection accuracy will decrease if a network is highly complex. In addition, a dendrogram to show the hierarchical relationships between each node and subgraph is drawn as one of the outcomes of the subgraph detection by the algorithm. Therefore, in this study, the greedy algorithm was used as a subgraph detection method, and the calculated subgraphs were discussed as core elements of human-ocean relations.

In addition, to investigate the content of the subgraphs in the obtained network in more detail, a series of network analysis measures for each node were calculated by focusing on the following three types of centralities: degree centrality, betweenness centrality, and eigenvector centrality. These three variables are popular centrality measures for nodes within a network (Freeman 1978). The degree centrality of each node refers to the number of edges that a node has (Wasserman and Faurst 1994). Betweenness centrality quantifies the number of times a node acts as a bridge along the shortest path between two other nodes, and this represents the degree to which nodes stand between each other as a hub (Newman 2010). Eigenvector centrality calculates the centrality of nodes connected to a targeted node, and this centrality represents the influence of a node in a network
(Newman 2010). Given these characteristics of network centralities, we used eigenvector centralities of respective nodes to interpret the meaning of detected subgraphs. After the interpretation of the subgraphs both in the Workshop and Survey results, we categorized them into groups of different meaning. In this categorization process, we utilized a qualitative content analysis method because to add more validity to capture the genuine meaning of human-ocean relationships that people perceive, rather than solely relying on the quantitative calculation by network analysis. Again, all the coauthors and other several experts joined this interpretation process, confirming its legitimacy. Through this iterative, i.e. a mixed method of qualitative and quantitative content analysis, we believe a more robust and valid plural valuation was achieved.

By interpreting the meaning of core elements, we were able to discuss the policy implications and possibilities of this method. Notably, the visualization of human-ocean relations was further polished by communication designers to ensure that the place-based valuation results of people's values were the central focus in the conservation planning process. To promote the communication of the scientific valuation results with local (and beyond local) stakeholders, we included artistic infographics that were constructed through collaborations with the communication designers (Fig. 2).

\section{Results}

\section{Demographic structure of survey participants}

We obtained a survey participant population with the demographic composition shown in Table 2. Compared with the source (mother) population (Ministry of Internal Affairs and Communication 2015), the average age of the survey participants was slightly higher than that in the mother population, and the proportion of female residents among the participants was apparently less than that in the mother population. Even though official statistics were not available for the proportion of local and immigrant residents, one community official reported that the local population was around $60 \%$ of the total population (Sugimoto 2016). Additionally, although there were no official statistics or published/gray literature on the average length of residence, 19.2(years) or more should be considered as the appropriate time frame that sufficiently represents the perspective of the locals. Given these statistics, the local population also seems to have been underrepresented in the survey participant population versus the mother population. As for the Workshop, eight fishers, seven conservation professionals, including local policymakers, researchers, and activists, and six community organization representatives participated. 
Table 2 Structure of survey participants

$\begin{array}{ll}\begin{array}{l}\text { Survey participants } \\ (N=153)\end{array} & \begin{array}{l}\text { Source } \\ \text { population } \\ (N=47,564)\end{array}\end{array}$

\begin{tabular}{lll}
\hline Age & & \\
Mean & 53.2 & 42.5 \\
Min & 19 & $\mathrm{n} / \mathrm{a}$ \\
Max & 90 & $\mathrm{n} / \mathrm{a}$ \\
Gender & & \\
Male & 104 & 23,659 \\
Female & 49 & 24,905 \\
Length of residence & & \\
Mean & 19.2 & $\mathrm{n} / \mathrm{a}$ \\
Min & 0 & $\mathrm{n} / \mathrm{a}$ \\
Max & 90 & $\mathrm{n} / \mathrm{a}$ \\
Birth origin & & \\
Local & 31 & $\mathrm{n} / \mathrm{a}$ \\
Immigrant & 122 & $\mathrm{n} / \mathrm{a}$ \\
\hline
\end{tabular}

\section{Five core elements of human-ocean relations}

Figures 3 and 4 show the visualized network of human-ocean relations according to the Survey and Workshop participants. There are seven and eight subgraphs for the Survey and Workshop results, respectively. By interpreting the contents (words) included in those, we devised the titles of the subgraphs as follows: "Sunburn," "Tourism," "Social relationship," "Attachment to the coral reef ecosystem," "Marine debris," "Island's weather and livelihood" and "Natural resources and livelihood" for the Survey results, and "Over tourism," "Sea color," "Beach swimming," "Local fishing custom," "Respect for ecological knowledge," "Environmental problems," "Typhoon," and "Attachment to the coral reef ecosystem" for the Workshop results. Then, we omitted "Sunburn" and "Tourism" in the Survey results and "Over tourism," "Sea color," and "Beach swimming" in the Workshop results because these had the lowest centrality variables (Degree 1, Betweenness 0, Eigenvector 0 , respectively) as shown in Tables 3 and 4 . By doing this, we found that there are five groups of meanings to be identified as core elements of human-ocean relations both in Survey and Workshop results, namely "Resources as livelihood means," "Local marine culture," "Attachment \& inspiration," "Anthropocene environmental problems," and "Respect and fear for nature." The details of each element are described below (also see Table 5 for the summary).

\section{Resources as livelihood means}

This group consists of the "Natural resources and livelihood" subgraph in the Survey results and the "Local fishing custom" subgraph in the Workshop results. In the natural resources and livelihood subgraph, the most influential was Fish-rc (Eigenvector 0.95), followed by Eat (Eigenvector 0.84), Seaweed-rc (Eigenvector 0.49), and Shellfish-rc (Eigenvector 0.25). In the local fishing custom subgraph, Fish-rc (Eigenvector 0.95) was the most influential, followed by Eat (Eigenvector 0.56), Fishing (Eigenvector 0.30), and Sell (Eigenvector 0.24). This group includes not only the fishery resources themselves, but also the importance of these resources to the livelihoods and traditional fishing customs of local residents, such as through sharing, buying, cooking (Survey), gathering, selling (Survey and Workshop), local community, and ecological knowledge (Workshop). Hence, we define this element as a fishery resource and its use for subsistence and livelihood.

\section{Local marine culture}

This element consists of the social relationship subgraph in the Survey result and Respect for ecological knowledge subgraph in the Workshop result. In the Survey result, Portrc (Eigenvector 0), Social relationship (Eigenvector 0), Culture (Eigenvector 0) were included, but none of these were found to be influential. In the Workshop results, Attachment (Eigenvector 0.38), Fishers-rc (Eigenvector 0.05) and Scenery (Eigenvector 0.05) were found to be influential. This element includes the way of connectedness between people and the sea on the island, such as through ports, culture (Survey), social relationship (Survey, Workshop) and fishers, respect, and fish markets (Workshop). Hence, we define this element as the local culture generated through the interconnection between people and the sea.

\section{Attachment and inspiration}

This element consists of the "Attachment to the coral reef ecosystem" subgraphs in both the Survey and Workshop results. In the Survey results, the most influential was See (Eigenvector 1.00), followed by Coral reef-rc (Eigenvector 0.74), and Beach_rc (Eigenvector 0.60). In the Workshop results, the most influential was Coral reef_rc (Eigenvector 1.00), followed by Work (Eigenvector 0.97) and Habitat (Eigenvector 0.57). In addition, the "Sea color," "Beach swimming" subgraphs in the Workshop result, even though these were omitted from the five core elements, can be categorized into this element. This element includes not only the coral reef and its ecosystem, but also the way in which people develop emotional bonds with these entities, such as through the attachment, conservation, education (Survey), recreation, beautiful (Survey and Workshop), culture, playing (Workshop), and "Sea color," "Beach swimming" subgraphs. Hence, we define this element as the people's emotional 
Fig. 3 Visualized human-ocean relations network (above: Survey; below: Workshop) (square represents resource categories (rc) which was detailed in 2.3.1 Data coding)
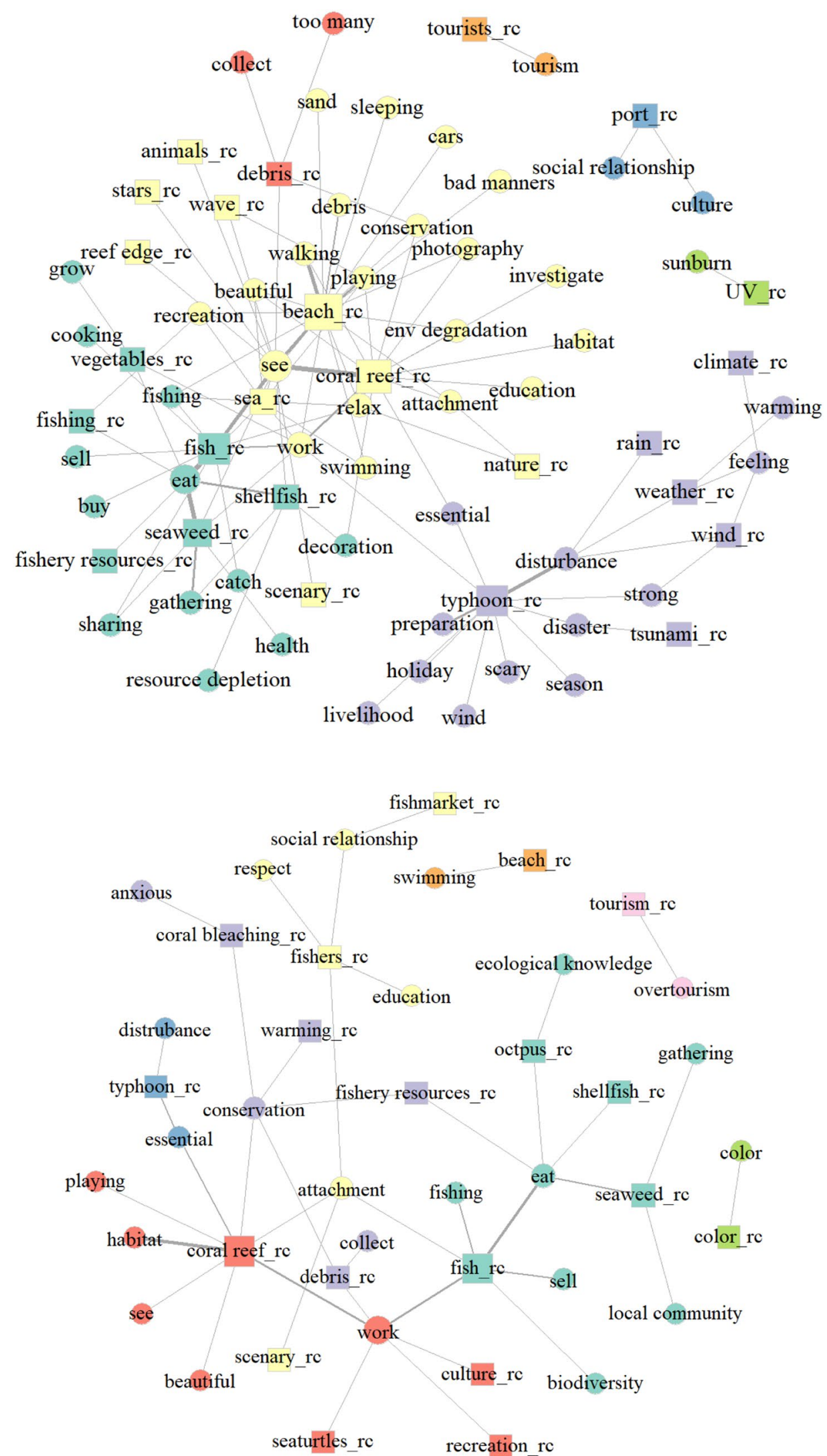


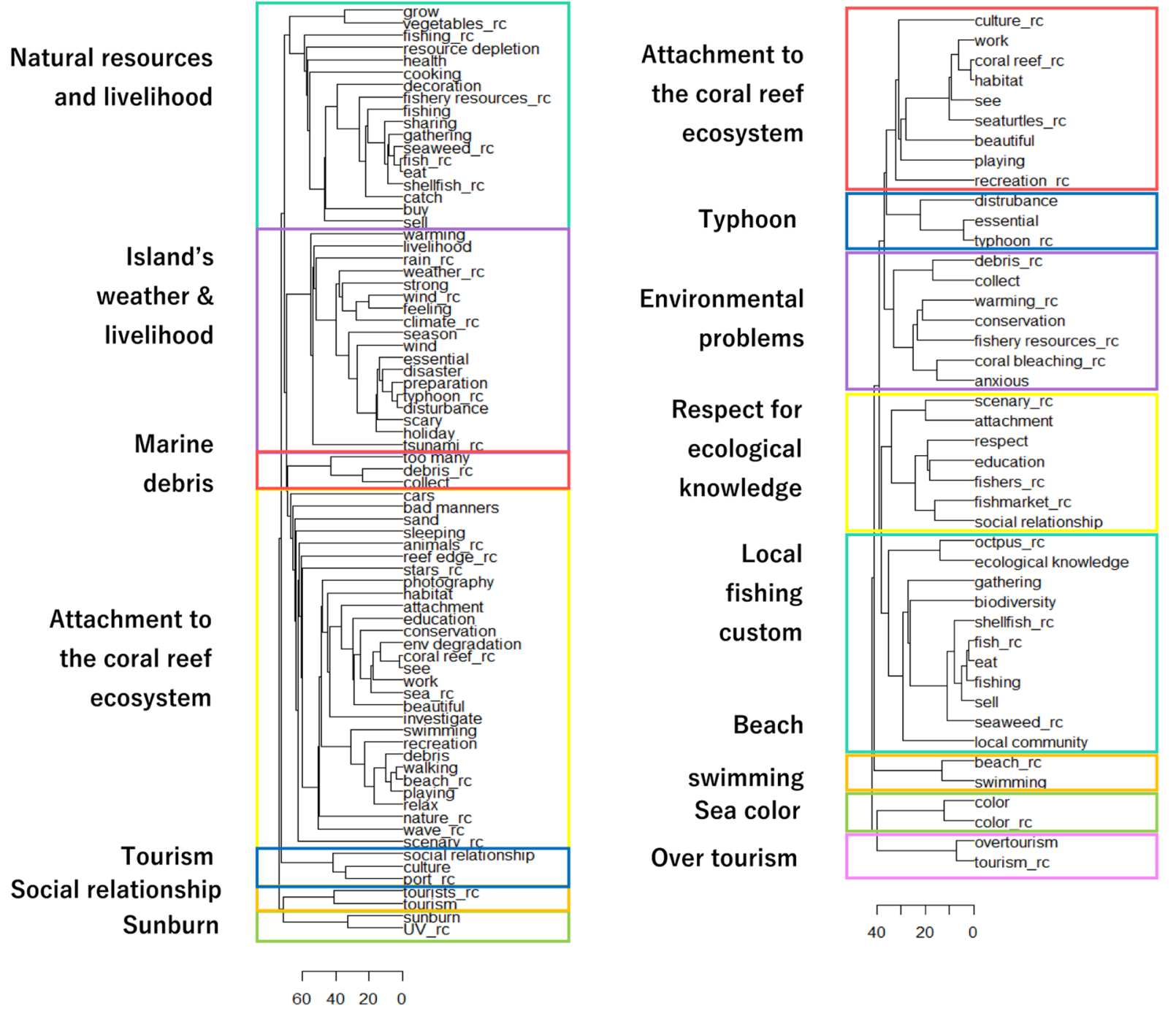

Fig. 4 Human-ocean relation network and its hierarchical dendrogram (left: Survey; right: Workshop)

bond with the coral reef ecosystem, and its utilization for educational and creative purposes.

\section{Anthropocene environmental problems}

This element consists of the "Marine debris" subgraph in the Survey result and the "Environmental problems" subgraph in the Workshop result. In the Survey result, the most influential was Debris_rc (Eigenvector 0.06). In the Workshop results, Conservation (Eigenvector 0.24) was the most influential, followed by Debris-rc (Eigenvector 0.22), Fishery resources-rc (Eigenvector 0.10). In addition, the "Tourism" (Survey), "Over tourism" (Workshop) subgraphs can be categorized into this element, even though these were omitted from the five core elements. This element includes marine environmental problems, which are caused by human activities such as the Debris_rc, collect (Survey and
Workshop), Coral bleaching_rc (Workshop) and "Tourism," "Over tourism" subgraphs. Hence, we define this element as environmental problems resulted from human activities in the Anthropocene.

\section{Respect and fear for nature}

This element consists of the "Island's weather and livelihood" subgraph in the Survey result and the "Typhoon" subgraph in the Workshop result. In the Survey result, the most influential was Essential (Eigenvector 0.06), followed by Typhoon-rc (Eigenvector 0.03), Disturbance (Eigenvector 0.01), Nature_rc (Eigenvector 0.01) and Preparation (Eigenvector 0.01). In the Workshop result, the most influential was Essential (Eigenvector 0.27), followed by Typhoon-rc (Eigenvector 0.07). In addition, the "Sunburn" subgraph in Survey result can be categorized into 
Table 3 Statistics for human-ocean relations network of Ishigaki (Survey results)

\begin{tabular}{|c|c|c|c|c|}
\hline S & Words included & Deg & Bet & Eigen \\
\hline 1 & Fish_rc & 10 & 286.5 & 0.95 \\
\hline 1 & Eat & 8 & 215 & 0.84 \\
\hline 1 & Seaweed_rc & 6 & 335.5 & 0.49 \\
\hline 1 & Shellfish_rc & 5 & 182 & 0.26 \\
\hline 1 & Fishing & 3 & 0 & 0.16 \\
\hline 1 & Gathering & 2 & 0 & 0.14 \\
\hline 1 & Sharing & 2 & 10 & 0.11 \\
\hline 1 & Catch & 1 & 0 & 0.10 \\
\hline 1 & Fishery resources_rc & 1 & 0 & 0.07 \\
\hline 1 & Vegetables_rc & 3 & 126 & 0.06 \\
\hline 1 & Buy & 1 & 0 & 0.04 \\
\hline 1 & Sell & 1 & 0 & 0.04 \\
\hline 1 & Decoration & 2 & 109 & 0.04 \\
\hline 1 & Fishing_rc & 2 & 4 & 0.04 \\
\hline 1 & Cooking & 1 & 0 & 0.03 \\
\hline 1 & Health & 1 & 0 & 0.02 \\
\hline 1 & Resource depletion & 1 & 0 & 0.01 \\
\hline 1 & Grow & 1 & 0 & 0.00 \\
\hline 2 & See & 12 & 520.5 & 1.00 \\
\hline 2 & Coral reef_rc & 15 & 410 & 0.74 \\
\hline 2 & Beach_rc & 19 & 562.5 & 0.60 \\
\hline 2 & Work & 7 & 788 & 0.44 \\
\hline 2 & Playing & 4 & 168 & 0.24 \\
\hline 2 & Sea_rc & 9 & 486 & 0.24 \\
\hline 2 & Walking & 2 & 0 & 0.23 \\
\hline 2 & Relax & 5 & 370 & 0.16 \\
\hline 2 & Conservation & 3 & 108.5 & 0.13 \\
\hline 2 & Env degradation & 2 & 0 & 0.11 \\
\hline 2 & Debris & 1 & 0 & 0.11 \\
\hline 2 & Attachment & 3 & 63 & 0.09 \\
\hline 2 & Beautiful & 3 & 53 & 0.08 \\
\hline 2 & Recreation & 3 & 0 & 0.08 \\
\hline 2 & Swimming & 2 & 0 & 0.06 \\
\hline 2 & Photography & 2 & 84 & 0.06 \\
\hline 2 & Education & 1 & 0 & 0.05 \\
\hline 2 & Wave_rc & 2 & 149.5 & 0.04 \\
\hline 2 & Scenary_rc & 1 & 0 & 0.03 \\
\hline 2 & Animals_rc & 1 & 0 & 0.03 \\
\hline 2 & Reef edge_rc & 1 & 0 & 0.03 \\
\hline 2 & Stars_rc & 1 & 0 & 0.03 \\
\hline 2 & Investigate & 1 & 0 & 0.03 \\
\hline 2 & Habitat & 1 & 0 & 0.03 \\
\hline 2 & Bad manners & 1 & 0 & 0.02 \\
\hline 2 & Cars & 1 & 0 & 0.02 \\
\hline 2 & Sand & 1 & 0 & 0.02 \\
\hline 2 & Sleeping & 1 & 0 & 0.02 \\
\hline 2 & Nature_rc & 2 & 61.5 & 0.01 \\
\hline 3 & Typhoon_rc & 11 & 912 & 0.03 \\
\hline 3 & Wind_rc & 3 & 366 & 0.00 \\
\hline
\end{tabular}

Table 3 (continued)

\begin{tabular}{|c|c|c|c|c|}
\hline $\mathrm{S}$ & Words included & Deg & Bet & Eigen \\
\hline 3 & Weather_rc & 3 & 70 & 0.00 \\
\hline 3 & Tsunami_rc & 1 & 0 & 0.00 \\
\hline 3 & Rain_rc & 1 & 0 & 0.00 \\
\hline 3 & Climate_rc & 1 & 0 & 0.00 \\
\hline 3 & Disturbance & 4 & 190 & 0.01 \\
\hline 3 & Preparation & 1 & 0 & 0.01 \\
\hline 3 & Essential & 2 & 102 & 0.06 \\
\hline 3 & Feeling & 3 & 66 & 0.00 \\
\hline 3 & Disaster & 2 & 66 & 0.00 \\
\hline 3 & Livelihood & 1 & 0 & 0.00 \\
\hline 3 & Season & 1 & 0 & 0.00 \\
\hline 3 & Scary & 1 & 0 & 0.00 \\
\hline 3 & Holiday & 1 & 0 & 0.00 \\
\hline 3 & Strong & 2 & 420 & 0.00 \\
\hline 3 & Warming & 1 & 0 & 0.00 \\
\hline 3 & Wind & 1 & 0 & 0.00 \\
\hline 4 & Debris_rc & 4 & 185.5 & 0.06 \\
\hline 4 & Collect & 1 & 0 & 0.00 \\
\hline 4 & Too many & 1 & 0 & 0.00 \\
\hline 5 & Port_rc & 2 & 1 & 0.00 \\
\hline 5 & Social relationship & 1 & 0 & 0.00 \\
\hline 5 & Culture & 1 & 0 & 0.00 \\
\hline 6 & Tourists_rc & 1 & 0 & 0.00 \\
\hline 6 & Tourism & 1 & 0 & 0.00 \\
\hline 7 & UV_rc & 1 & 0 & 0.00 \\
\hline 7 & Sunburn & 1 & 0 & 0.00 \\
\hline
\end{tabular}

$S$ subgraph number, Deg. degree centrality, Bet. betweenness centrality, Eigen. eigenvector centrality

this element, even though it was omitted from the five core elements. This element includes both meteorological phenomena and the way local people perceive these phenomena with a sense of fear and respect, with associations such as essential, typhoons, disturbances, and fear. Hence, we define this element as the influence of meteorological events on livelihoods, the people's sense of fear, and the respect for nature.

\section{Discussion}

Five core elements of human-ocean relations on Ishigaki Island were extracted as described above. Here, we discuss the policy implications and methodological possibilities and challenges posed by this study. 
Table 4 Statistics for human-ocean relations network of Ishigaki (Workshop results)

\begin{tabular}{|c|c|c|c|c|}
\hline$S$ & Words included & Deg & Bet & Eigen \\
\hline 1 & Fish_rc & 6 & 116 & 0.95 \\
\hline 1 & Eat & 5 & 195 & 0.56 \\
\hline 1 & Fishing & 1 & 0 & 0.30 \\
\hline 1 & Sell & 1 & 0 & 0.24 \\
\hline 1 & Seaweed_rc & 3 & 69 & 0.14 \\
\hline 1 & Biodiversity & 1 & 0 & 0.12 \\
\hline 1 & Shellfish_rc & 1 & 0 & 0.11 \\
\hline 1 & Octpus_rc & 2 & 35 & 0.07 \\
\hline 1 & Local community & 1 & 0 & 0.02 \\
\hline 1 & Gathering & 1 & 0 & 0.02 \\
\hline 1 & Ecological knowledge & 1 & 0 & 0.01 \\
\hline 2 & Attachment & 4 & 233 & 0.38 \\
\hline 2 & Fishers_rc & 4 & 133 & 0.05 \\
\hline 2 & Scenary_rc & 1 & 0 & 0.05 \\
\hline 2 & Social relationship & 2 & 35 & 0.01 \\
\hline 2 & Education & 1 & 0 & 0.01 \\
\hline 2 & Respect & 1 & 0 & 0.01 \\
\hline 2 & Fishmarket_rc & 1 & 0 & 0.00 \\
\hline 3 & Conservation & 5 & 299 & 0.24 \\
\hline 3 & Debris_rc & 3 & 83 & 0.22 \\
\hline 3 & Fishery resources_rc & 2 & 175 & 0.10 \\
\hline 3 & Coral bleaching_rc & 2 & 35 & 0.03 \\
\hline 3 & Warming_rc & 1 & 0 & 0.03 \\
\hline 3 & Collect & 1 & 0 & 0.03 \\
\hline 3 & Anxious & 1 & 0 & 0.00 \\
\hline 4 & Coral reef_rc & 8 & 349 & 1.00 \\
\hline 4 & Work & 6 & 110 & 0.97 \\
\hline 4 & Habitat & 1 & 0 & 0.57 \\
\hline 4 & See & 1 & 0 & 0.19 \\
\hline 4 & Seaturtles_rc & 1 & 0 & 0.18 \\
\hline 4 & Beautiful & 1 & 0 & 0.13 \\
\hline 4 & Playing & 1 & 0 & 0.13 \\
\hline 4 & Culture_rc & 1 & 0 & 0.12 \\
\hline 4 & Recreation_rc & 1 & 0 & 0.12 \\
\hline 5 & Essential & 2 & 68 & 0.27 \\
\hline 5 & Typhoon_rc & 2 & 35 & 0.07 \\
\hline 5 & Disturbance & 1 & 0 & 0.01 \\
\hline 6 & Beach_rc & 1 & 0 & 0.00 \\
\hline 6 & Swimming & 1 & 0 & 0.00 \\
\hline 7 & Color_rc & 1 & 0 & 0.00 \\
\hline 7 & Color & 1 & 0 & 0.00 \\
\hline 8 & Tourism_rc & 1 & 0 & 0.00 \\
\hline 8 & Overtourism & 1 & 0 & 0.00 \\
\hline
\end{tabular}

$S$ subgraph number, Deg. degree centrality, Bet. betweenness centrality, Eigen. eigenvector centrality

\section{Five proposed elements of human-ocean relations and associated implications for future research and policy agendas}

\section{Significant limitations of past assessments of Okinawan coral reef ES: over (and merely positive) valuation of tourism and recreation}

The previous coral reef ES assessment obtained valuations of 239.9 billion JPY (2.8 billion USD) for tourism and recreation, 10.7 billion JPY (123 million USD) for commercial fishery resources, and 7.5-83.9 billion JPY (86.2-964.4 million USD) for coastal protection (MOE Japan 2010). These three valuation categories apparently correspond to cultural, provisioning, and regulating ES, respectively (MA 2005). However, based on the extracted human-ocean relations in this study, it is now important to point out two major limitations of the past valuation. The first relates to the over (and merely positive) valuation of tourism and recreation as one of the biggest causes of current marine environmental issues, and the second relates to the shadowing of the other four core elements of values that people hold toward the ocean.

As for the over and merely positive valuation of tourism and recreation, our results showed that many local residents hold cautious views on these issues. The "Anthropocene environmental problems" group, extracted as one of the five core elements, provides the most significant evidence for this limitation, as the results indicate that recreational coastal usage including tourism has resulted in negative environmental impacts. This negative perception of tourism was particularly strong among the workshop participants, which are the fishers and conservation policy makers. Some narratives during the Workshop are presented in Photo 2, in which participants complained about the overuse of beaches and coastal waters, e.g., "marine environments are declining in every part, but only tourism is rising," "the manners of some tourism operators are getting worse, including some accidents, which resulted in the tourists' death." This could have been the result of the focus on monetary values of tourism and recreation in the past ES assessment, such as in the cultural ES category, in addition to the governmental policy that promotes tourism by describing the site as a "subtropical, exotic paradise island" (Tada 2004, 2008). It is worth noting that the local residents also enjoy coastal recreation activities such as swimming, relaxing, and walking as shown vividly in the "Attachment \& inspiration" element. Hence, the problem is that this element has been evaluated as excessively positive in the past NCP/ES research and 
Table 5 Extracted subgraphs and five core elements derived by integrating the meanings of the subgraphs

\begin{tabular}{ll}
\hline Extracted subgraphs & Five core elements \\
\hline Natural resources and livelihood (S) & Resources as livelihood means \\
Local fishing custom (W) & \\
Social relationship (S) & Local marine culture \\
Respect for ecological knowledge (W) & \\
Attachment to the coral reef ecosystem (S,W) & Attachment and inspiration \\
Marine debris (S) & Anthropocene environmental problems \\
Environmental problems (W) & \\
Island's weather and livelihood (S) & Respect and fear for nature \\
Typhoon (W) & \\
\hline
\end{tabular}

policy discourse, rather than the recreational value of the coral reef ecosystem itself. The negative impacts of tourism on coral reef ecosystems have been reported in other countries/regions as well (Gil et al. 2015; Wong et al. 2019), therefore it needs to be carefully monitored and appropriately addressed globally.

It is also insightful that this element was extracted as one of the significant five values of human-ocean relations, potentially implying that the value of nature cannot escape from the human-induced problems in the Anthropocene.

As the past ES assessment noted "there may be a limit to fully quantify ecosystem services," and our findings are suggestive of four elements besides recreation. In regard to "Resources as livelihood means," "Local marine culture," "Attachment and inspiration," and "Respect and fear for nature," it can be presumed that these four elements have been under-evaluated or even disregarded in the previous ES assessment framework. In light of this, important implications around the "new" elements are detailed below.

\section{Respect and fear for nature: "Negative" but essential contributions of nature to people}

One of the most notable results in this study is related to the "Respect and fear for nature", element, which reflects how local residents perceive nature in the Okinawan Islands, and probably other regions in the Asia-pacific as well. As shown in Fig. 4, the node "typhoon" was connected with both "disturbance" and "essential," and "essential" was categorized by phrases such as "important for a healthy ocean," "purification," and "foundation (for nature and human)." Here, we deduce that the people held the perception that even "negative" natural phenomena like disasters (e.g., typhoons) are not merely negative, but that the people rather are "accepting" of such natural events, being ambiguous in that they encompass both positive (e.g., essential for ecosystems and livelihoods) and negative (e.g., scary, disturbing to livelihoods) aspects. This ambiguity of nature has been assumed as an important factor for shaping the worldviews and peoples' characteristics in the Asian monsoon climate zone (Watsuji 1979; Berque 1992) as well as the notion of sacredness, such as "Kami (Gods)" in Japanese culture (Nomoto 2006). As Díaz et al. (2018) discussed, NCP can be either perceived as positive (benefits) or negative (decrements) according to the specific economic/social/cultural context of the stakeholders, and the results may even vary among the same stakeholders according to the spatial or temporal context. In addition, Muradian and Pascual (2018) proposed seven relational models (RM), which consist of the following eight elementary typologies: detachment, domination, devotion, stewardship, wardship, ritualized exchange, and utilization. According to this model, the "Respect and fear for nature" element may fit into "Stewardship," in which "Nature is perceived as a comprehensive system that encompasses humans" (Muradian and Pascual 2018, p. 10). The authors also argue that when different social groups have their own RMs that are incommensurable, the aggregation of values becomes extremely challenging and conflicts become intractable (Muradian and Pascual 2018, p. 13). There are plenty of examples that illustrate this conflict situation in relation to the "Respect and fear for nature" element in Japan, including the controversial construction plans of seawalls along coastal communities, which have been especially accelerated after the 2011 Great East Japan Earthquake (e.g., Yamashita 2020). Given this, we argue that this element could be one of the most critical points for understanding human-nature relationships in Japan and possibly other Asian countries and regions.

We observed during, before, and after the Workshop and Survey presented here that this element is of critical importance among local people, which is also related to the spiritual and religious value explained in "Human-ocean relations on the island". Hence, careful investigations need to follow this study in order to clarify if and how this worldview could enhance the resilience of ecosystems. 


\section{Externalized importance of relational values on Ishigaki Island}

By extracting the human-ocean relation elements, we notice that some of these elements are closely related to relational values, particularly the following two core elements: "Resources as livelihood means" and "Local marine culture." A primary motivation for the recent introduction of relational values (Chan et al. 2016) concepts into the sustainability discourse was to find a language to facilitate decision-making that reflects the diverse ways in which people, particularly people from non-Western, local communities, articulate what matters to them with respect to human-nature relationships (as they are called from a Western perspective) (Gould et al. 2019; Himes and Muraca 2018). It is obvious from our results that fishery resources as food are of great importance not only as "nutrients," but also as a bond to connect people through local customs. In Okinawan communities, there are customs called kousai, through which residents usually exchange and share various goods, such as vegetables and seafood, to maintain social relationships (Sugimoto 2016). In consideration of this, fishery resources are vital for the cohesion of the island community as well. The avoidance of fishery resource depletion is, therefore, also important to the avoidance of a decline in community ties on such an island. We argue that conservation efforts will be more successful if the recent theoretical development of NCP is used to enhance conservation decision-making, which will be inclusive of this relational perspective. At the same time, decision-makers need to be well aware of the risk that environmental degradation could critically affect social relationships and community customs beyond natural environmental degradation in local communities with dense social ties.

\section{Attachment to coral reef ecosystems}

Our results also included other components, which have been listed as sub-categories of CES, such as a sense of place, inspiration, and education in the "Attachment to the coral reef ecosystem" element. A sense of place, listed as one of the examples of CES (MA 2005), has been deeply investigated in a few studies (e.g., Urquhart and Acott 2014). Place attachment is a typical sub-concept, and it involves an emotional bond, usually positive, between individuals or groups and their environment (Altman and Low 1992). This concept has gained attention in the literature on human-nature relations (Masterson 2017; van Putten 2018). For instance, it has been suggested that place attachment enhances the adaptive capacity, and data suggest that social capital, local knowledge, and reciprocal networks facilitate the adaptation to incremental social-ecological
Table 6 Top 5 nodes with regard to Eigenvector centralities among the Workshop and Survey results

\begin{tabular}{llll}
\hline Eigenvector & & & \\
\hline Survey & & Workshop & \\
\hline See & 1.00 & Coral reef_rc & 1.00 \\
Fish-rc & 0.95 & Work & 0.97 \\
Eat & 0.84 & Fish_rc & 0.95 \\
Coral reef-rc & 0.74 & Habitat & 0.57 \\
Beach-rc & 0.60 & Eat & 0.56 \\
\hline
\end{tabular}

change (Eakin et al. 2016; Marshall et al. 2012). Chapin and Knapp (2015) argued that stewardship can be fostered by place attachment, produced through repeated personal experiences filtered through identity and social contexts. Ives et al. (2018) argued that human-nature connectedness is a multifaceted concept, which requires that "emotional attachments and affective responses" be incorporated into analyses. Hence, we judge that it was reasonable and important to identify the five elements, including place attachment, as being related to human-ocean connectedness in this study.

\section{Implication from the comparison between Workshop and Survey results: "consuming the seascape" as a result of tourism promotion}

Although this paper did not specifically investigate the differences of extracted words and subgraphs among stakeholder groups, we gained several insights on differences between the Workshop and Survey participant groups with regard to the human-ocean relationships. Table 6 shows the influential words with the five highest Eigenvector centralities between the Workshop and Survey results. Coral reefrc, Fish-rc, Eat, are commonly prioritized in both groups, yet Work and Habitat were uniquely detected among Workshop result, while See and Beach-rc were uniquely detected among the Survey result. We can interpret from this result that people in Workshop, who have close and direct relationships with the ocean by interacting with the coral reefs through their "Work," have a more "ecological" perception on it, symbolically represented by the word "Habitat." In fact, we observed during the Workshop among fishers and conservation officers that they frequently mentioned specific species names, with explanations of their behavioral or ecological characteristics. Furthermore, we also observed that younger participants (both fishers or conservation officers) expressed respect and admiration for the deep ecological knowledge that are held among elderly, experienced people in the community. These were also extracted as a subgraph titled "Respect for ecological knowledge" (Figs. 3 and 4). In contrast, See and Beach-rc were uniquely detected among the Survey result, which may imply that the seascape 
as an ornamental object may symbolically represent the human-ocean relationship among the general public on the Island, or the "average" relationship among residents whose interactions with the ocean varies from shallow (e.g., without any direct use) to deep (e.g., constant direct use). As shown in Table 2, the local population seems to have been underrepresented than the mother population in the present study, which could mean that the Survey results might over-represent the human-ocean relationship among immigrants. If that is the case, the results could also have similarity with those among people without residence on the island, such as tourists. This would also be consistent with the recent finding by Sugino et al. (2017) that the topic group of "Okinawan coral reef sea" occurs among Japanese citizens when asking about the image of the sea. Again, this may be caused by the past tourism promotion of Okinawa as a "subtropical, exotic paradise island" (Tada 2004, 2008), which also could have resulted in an increase in the usage of the seascape as an ornamental object. The Okinawan economy has commonly said to have been "distorted" because of its dependence on the 3Ks: "Kichi, Kankou, Kokyo-koji" in Japanese, meaning "the bases, tourism, and public money (subsidies and public works)" (e.g., Pajon 2010). This characteristic of the Okinawan economy is likely to enhance the structural dependence on tourism development, which significantly depends on the consumption of ornamental seascape. Thus, conservation planning in this region needs to put local plural values at the center, rather than the current trajectory which is the over-utilization of the seascape. In this regard, future works need to follow the present study to clarify the variation of values among people, represented by demographic variables such as age, gender, birth origin, occupation, and length of residence. This is particularly true because the present work applied two different methods of data collection: Workshop and Survey. Notably, the different methods used in this study could have caused people to describe their relationship with the ocean differently i.e., the Workshop could be potentially "more deliberative" than the Survey. The method utilized in this work will also be beneficial for investigating how different people value the "same ocean" and for identifying geographically overlapping spaces/resource in quantifiable terms, for example, through network centrality variables.

\section{From plural valuation of nature toward transformative governance}

As mentioned earlier, accumulating evidence has proved that land (agricultural) - based pollution is one of the critical factors causing coral reef degradation in the Okinawan Islands including Ishigaki, suggesting that it can be mitigated if appropriate policy measures are taken (Hasegawa 2011; Hongo and Yamano 2013; Harii et al. 2014; Yamano et al.
2015). However, there is another serious source of landbased pollution all around the Okinawan Islands-national security issues (Williams 2013), indicating that some of the reef dependent communities are threatened not only ecologically but also politically (Davis 2011). The authors suspect this kind of political vulnerability may cause low sense of agency among local residents regarding making decisions about the local environmental in "democratic" ways, or the political and environmental threats might often be too "powerful" to be tackled only by local residents. Under such circumstances, management decisions without addressing the critical threats facing coral reef ecosystems can be easily pursued because they are politically more pragmatic than more meaningful alternatives (Pressey et al., 2017; Bellwood et al. 2019; Morrison et al. 2020). In light of this, integrated intervention with synergetic effects is urged under the current state of ecosystem decline accelerated by climate change (Makino et al.2020; Morrison et al. 2020). This should be taken into consideration by national and prefectural governments but has not been easy in Japanese oceanrelated policy arenas (Wakita and Yagi 2013; Wakita 2018; Makino et al. 2020). To promote such transformative change of coral reef governance, it is desirable that the findings of this paper will be reached by not only local and national policy makers but also by more diverse stakeholders such as citizens and private companies, as suggested by recent works on the transnational, multiscale governance of Anthropocene reefs (Gurney et al. 2017; Bellwood et al. 2019; Morrison et al. 2020). To this end, the collaboration with communication designers should be one of the critical features of plural valuation of human-nature relationships, because it could trigger such transformative governance of ecosystems including coral reefs, through the sharing of the local plural values among transnational stakeholders. Through collaboration with designers, this work metaphorically visualized the ocean as a mother (Fig. 5). The metaphor of "Mother Ocean" can also describe the significant limitation of past ES assessments: it could be likened to placing a monetary valuation on our own mothers (e.g., through daily costs to raise children), not only among scientists and policy makers but also for much wider audiences. ${ }^{1}$

\section{Conclusions}

This study is among the first to extract and visualize place-based human-ocean relations in an Asian country. Through a mixed method of qualitative content analysis and

\footnotetext{
${ }^{1}$ It has been suggested that anthropomorphism can enhance the connectedness to or conservation behavior toward nature (Liu et al. 2019; Tam et al. 2013). This evidence could also suggest the great potential of the "Mother Ocean" as a metaphor.
} 
Fig. 5 Mother Ocean Infographic, showing a summary of the findings of this work

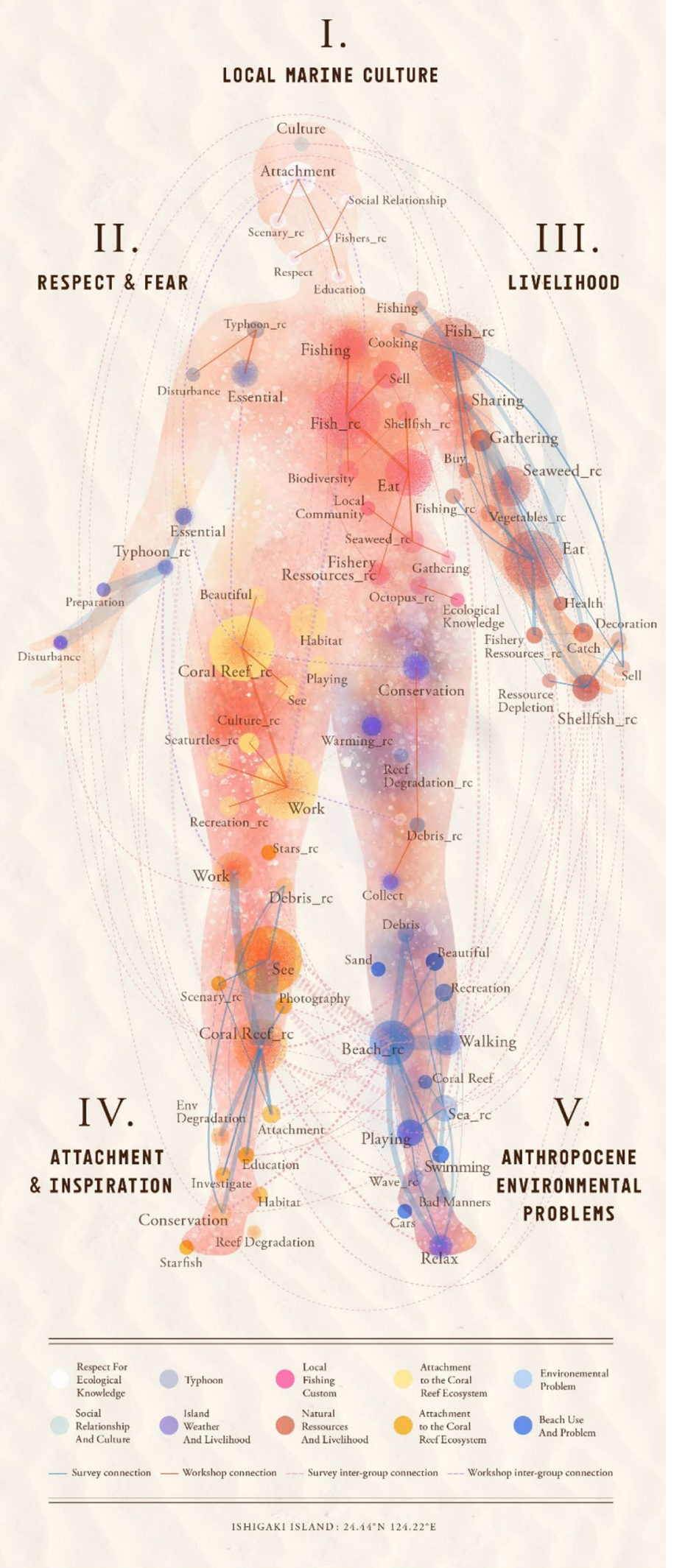


quantitative network analysis on text data obtained by questionnaires with open-ended questions, we extracted five core elements of human-ocean relationship in Yaeyama Islands, Okinawa, Japan. Our results indicate that future conservation planning efforts should incorporate an awareness of the plural values that local people hold toward the ocean on the Okinawan Islands and elsewhere such as "Attachment and inspiration," "Local marine culture," "Respect and fear for nature," all of which have been under-evaluated or even ignored in the past ES assessment and the conservation measures that followed. We hope that our findings will be applied to other areas, especially to the local communities of understudied Asia-pacific countries and regions, both theoretically and methodologically. We also discussed how human-nature plural valuation could contribute to the promotion of transformative change of coral reef governance in the Anthropocene. Findings of this work should be placed at the beginning of this transformative process, so that the kind of values that need to be sustained will focus on the perspectives of the local people who live alongside coral reef ecosystems.

Acknowledgements We sincerely express our gratitude to all local participants who contributed their valuable time to this work. In addition, we particularly thank Drs. Atsushi Nanami, Shingo Watari, Mitsutaku Makino, Hiroya Yamano, Tatsuo Nakai, Hiroe Ishihara, Mr. Yosuke Kuramoto, and many others for their support and insights to accomplish this work. We thank NOSIGNER for creating the Infographics (Figs. 3 and 5), and Ms. Yumi Sato, Mr. Eisuke Tachikawa for the overall communication design of this work.

Funding This study was supported by the Environmental Research and Technology Development Fund (S-15 Predicting and Assessing Natural Capital and Ecosystem Services (PANCES)) of the Ministry Of the Environment, Japan, and by the Grant-In-Aid for Young Scientists (JSPS KAKENHI), Grant Number 19H20489, of the Ministry of Education, Culture, Sports, Science and Technology, Japan.

\section{Declarations}

Conflict of interest The authors declare that they have no conflict of interest.

Open Access This article is licensed under a Creative Commons Attribution 4.0 International License, which permits use, sharing, adaptation, distribution and reproduction in any medium or format, as long as you give appropriate credit to the original author(s) and the source, provide a link to the Creative Commons licence, and indicate if changes were made. The images or other third party material in this article are included in the article's Creative Commons licence, unless indicated otherwise in a credit line to the material. If material is not included in the article's Creative Commons licence and your intended use is not permitted by statutory regulation or exceeds the permitted use, you will need to obtain permission directly from the copyright holder. To view a copy of this licence, visit http://creativecommons.org/licenses/by/4.0/.

\section{References}

Altman I, Low S (1992) Place attachment. Plenum Press, New York

Barnes ML, Lynham J, Kolberg K, Leung PS (2016) Social networks and environmental outcomes. Proc Nat Acad Sci USA 113(23):6466-6471. https://doi.org/10.1073/pnas.1523245113

Bellwood DR, Pratchett MS, Morrison TH, Gurney GG, Hughes TP, Álvarez-Romero JG, Day JC, Grantham R, Grech A, Hoey AS, Jones GP (2019) Coral reef conservation in the Anthropocene: confronting spatial mismatches and prioritizing functions. Biol Conserv 236:604-615. https://doi.org/10.1016/j.biocon.2019. 05.056

Berque A (1992) Le sauvage et l'artifice: les Japonais devant la nature. Chikuma-shobo, Tokyo (in Japanese translated by Katsuhide Shinoda)

Bodin Ö, Crona BI (2009) The role of social networks in natural resource governance: what relational patterns make a difference? Global Environ Change 19(3):366-374. https://doi.org/10.1016/j. gloenvcha.2009.05.002

Chakrabortya S, Gasparatos A (2019) Community values and traditional knowledge for coastal ecosystem services management in the "satoumi" seascape of Himeshima island, Japan. Ecosyst Serv 37:100940. https://doi.org/10.1016/j.ecoser.2019.100940

Chan KMA et al (2012a) Where are cultural and social in ecosystem services? A framework forconstructive engagement. Bioscience 62(8):744-756. https://doi.org/10.1525/bio.2012.62.8.7

Chan KMA, Satterfield T, Goldstein J (2012b) Rethinking ecosystem services to better address and navigate cultural values. Ecol Econ 74:8-18. https://doi.org/10.1016/j.ecolecon.2011.11.011

Chan KMA et al (2016) Opinion: why protect nature? Rethinking values and the environment. Proc Nat Acad Sci USA 113(6):14621465. https://doi.org/10.1073/pnas. 1525002113

Chapin FS, Knapp CN (2015) Sense of place: a process for identifying and negotiating potentially contested visions of sustainability. Environ Sci Policy 53:38-46. https://doi.org/10.1016/j. envsci.2015.04.012

Chen M, Kuzmin K, Szymanski B (2014) Community detection via maximization of modularity and its variants. IEEE Trans Comput Soc Syst 1:46-65

Christie M, Martín-López B, Church A, Siwicka E, Szymonczyk P, Sauterel JM (2019) Understanding the diversity of values of "Nature's contributions to people": insights from the IPBES Assessment of Europe and Central Asia. Sustain Sci 14(5):1267-1282. https://doi.org/10.1007/s11625-019-00716-6

Clauset A, Newman ME, Moore C (2004) Finding community structure in very large networks. Phys Rev E 70(6):066111

Cooper N, Brady E, Steen H, Bryce R (2016) Aesthetic and spiritual values of ecosystems: recognising the ontological and axiological plurality of cultural ecosystem 'services.' Ecosyst Serv 21:218-229. https://doi.org/10.1016/j.ecoser.2016.07.014

Crona B, Bodin Ö (2006) What you know is who you know? Communication patterns among resource users as a prerequisite forco-management. Ecol Soc 11(2):7. https://doi.org/10.1038/ nature 09798

Cvitanovic C, Cunningham R, Dowd AM, Howden SM, van Putten EI (2017) Using social network analysis to monitor and assess the effectiveness of knowledge brokers at connecting scientists and decision-makers: an Australian case study. Environ Policy Gov 27(3):256-269. https://doi.org/10.1002/eet.1752

Daniel TC et al (2012) Contributions of cultural services to the ecosystem services agenda. Proc Nat Acad Sci USA 109(23):8812-8819. https://doi.org/10.1073/pnas.1114773109

Danowski JA (1993) Network analysis of message content. In: Richards WD Jr, Barnett GA (eds) Progress in communication sciences IV. Ablex, Norwood, NJ, pp 197-221 
David RB, Morgan SP, Tiffany HM, Georgina GG, Terry PH, Álvarez-Romero JG, Jon CD, Ruby G, Alana G, Andrew SH, Geoffrey PJ, John MP, Sterling BT, Erika T, Rebecca W, Graeme SC (2019) Coral reef conservation in the Anthropocene: confronting spatial mismatches and prioritizing functions. Biol Conserv 236:604-615. https://doi.org/10.1016/j.biocon.2019.05.056

Davis S (2011) The US military base network and contemporary colonialism: power projection, resistance and the quest for operational unilateralism. Political Geogr 30:215-224. https:// doi.org/10.1016/j.polgeo.2011.04.003

Deo N (2017) Graph theory with applications to engineering and computer science. Courier Dover Publications

Díaz S et al (2018) Assessing nature's contributions to people. Science 359(6373):270-272. https://doi.org/10.1126/science. aap8826

Eakin H, York A, Aggarwal R, Waters S et al (2016) Cognitive and institutional influences on farmers' adaptive capacity: insights into barriers and opportunities for transformative change in central Arizona. Reg Environ Change 16(3):801-814. https://doi. org/10.1007/s10113-015-0789-yEnqvist

FeldmanSanger RJ (2007) The text mining handbook: advanced approaches in analyzing unstructured data. Cambridge University Press, Cambridge, NY

Fish-rchurch A, Winter M (2016) Conceptualising cultural ecosystem services: a novel framework for research and critical engagement. Ecosyst Serv 21:208-217. https://doi.org/10.1016/j.ecoser.2016. 09.002

Fortunato S (2010) Community detection in graphs. Phys Rep 486:75-174

Freeman LC (1978) Centrality in social networks conceptual clarification. Soc Netw 1(3):215-239. https://doi.org/10.1016/03788733(78)90021-7

Gil MA, Renfro B, Figueroa-Zavala B, Penié I, Dunton KH (2015) Rapid tourism growth and declining coral reefs in Akumal, Mexico. Mar Biol 162:2225-2233. https://doi.org/10.1007/ s00227-015-2748-z

Girvan M, Newman MEJ (2002) Community structure in social and biological networks. Proc Nat Acad Sci USA 99:7821-7826

Gómez-Baggethun E, de Groot R, Lomas PL, Montes C (2010) The history of ecosystem services in economic theory and practice: from early notions to markets and payment schemes. Ecol Econ 69(6):1209-1218. https://doi.org/10.1016/j.ecolecon.2009.11. 007

Gould RK et al (2015) A protocol for eliciting nonmaterial values through a cultural ecosystem services frame. Conserv Biol 29(2):575-586. https://doi.org/10.1111/cobi.12407

Gould RK, Pai M, Muraca B, Chan KMA (2019) He 'ike 'ana ia i ka pono (it is a recognizing of the right thing): how one indigenous worldview informs relational values and social values. Sustain Sci 14(5):1213-1232. https://doi.org/10.1007/ s11625-019-00721-9

Gurney GG, Blythe J, Adams H, Adger WN, Curnock M, Faulkner L, James T, Marshall NA (2017) Redefining community based on place attachment in a connected world. PNAS 114(38):1007710082. https://doi.org/10.1073/pnas.1712125114

Hardy GE, Barkham M (1994) Relationship between interpersonal attachment styles and work difficulties. Hum Relat. https://doi. org/10.1177/001872679404700302

Harii S, Hongo C, Ishihara M, Ide Y, Kayanne H (2014) Impacts of multiple disturbances on coral communities at Ishigaki Island, Okinawa, Japan, during a 15 year survey. Mar Ecol Prog Ser 509:171-180. https://doi.org/10.3354/meps 10890

Hasegawa H (2011) The decline of coral reef conditions caused by the extensive land modification: a case study of the shiraho area on Ishigaki Island, Okinawa, Japan. J Remote Sens Soc Jpn 31(1):73-86. https://doi.org/10.11440/rssj.31.73 (in Japanese)
Himes A, Muraca B (2018) Relational values: the key to pluralistic valuation of ecosystem services. Curr Opin Environ Sustain 35:1-7. https://doi.org/10.1016/j.cosust.2018.09.005

Hongo C, Yamano H (2013) Species-specific responses of corals to bleaching events on anthropogenically turbid reefs on Okinawa Island, Japan, over a 15-year period (1995-2009). PLoS ONE 8(4):e60952. https://doi.org/10.1371/journal.pone.0060952

Hori J, Tajima H, Makino M (2017) The analysis of stakeholders' interests in coral reef ecosystems and their services-a case study on the Sekisei Lagoon. J Coast Zone Stud 30(2):61-73 (in Japanese)

Hughes TP, Baird AH, Bellwood DR, Card M, Connolly SR, Folke C, Grosberg R, Hoegh-Guldberg O, Jackson JBC, Kleypas J, Lough JM, Marshall P, Nyström M, Palumbi SR, Pandolfi JM, Rosen B, Roughgarden J (2003) Climate change, human impacts, and the resilience of coral reefs. Science 301(5635):929-933. https://doi. org/10.1126/science.1085046

Hughes TP, Barnes ML, Bellwood DR, Cinner JE, Cumming GS, Jackson JBC, Kleypas J, Leemput IA, Lough JM, Morrison TH, Palumbi SR, Nes EH, Scheffer M (2017) Coral reefs in the anthropocene. Nature. https://doi.org/10.1038/nature22901

IPBES (2018) Summary for policymakers of the regional assessment report on biodiversity and ecosystem services for Asia and the Pacific of the Intergovernmental Science-Policy Platform on Biodiversity and Ecosystem Services. In: Karki M, Senaratna Sellamuttu S, Okayasu S, Suzuki W, Acosta LA, Alhafedh Y, Anticamara JA, Ausseil AG, Davies K, Gasparatos A, Gundimeda H, Faridah-Hanum I, Kohsaka R, Kumar R, Managi S, Wu N, Rajvanshi A, Rawat GS, Riordan P, Sharma S, Virk A, Wang C, Yahara T, Youn YC (eds). IPBES Secretariat, Bonn, Germany, $41 \mathrm{pp}$

IPBES (2019) Summary for policymakers of the global assessment report on biodiversity and ecosystem services of the Intergovernmental Science-Policy Platform on Biodiversity and Ecosystem Services. In: Díaz S, Settele J, Brondízio ES, Ngo HT, Guèze M, Agard J, Arneth A, Balvanera P, Brauman KA, Butchart SHM, Chan KMA, Garibaldi LA, Ichii K, Liu J, Subramanian SM, Midgley GF, Miloslavich P, Molnár Z, Obura D, Pfaff A, Polasky S, Purvis A, Razzaque J, Reyers B, Roy Chowdhury R, Shin YJ, Visseren-Hamakers IJ, Willis KJ, Zayas CN (eds). IPBES Secretariat, Bonn, Germany $56 \mathrm{pp}$

Ishihara H (2018) Relational values from a cultural valuation perspective: how can sociology contribute to the evaluation of ecosystem services? Curr Opin Environ Sustain 35:61-68. https://doi.org/ 10.1016/j.cosust.2018.10.016

Ishii HT et al (2010) Integrating ecological and cultural values toward conservation and utilization of shrine/temple forests as urban green space in Japanese cities. Landsc Ecol Eng 6(2):307-315. https://doi.org/10.1007/s11355-010-0104-5

Ives CD, Abson DJ, Wehrden H, Doeninger C et al (2018) Reconnecting with nature for sustainability. Sustain Sci 13:1389-1397. https://doi.org/10.1007/s11625-018-0542-9

Japan Satoyama Satoumi Assessment (2010) Satoyama—satoumi ecosystems and human wellbeing: socio-ecological production landscapes of Japan (summary for decision makers). United Nations University, Tokyo

Kayanne H, Suzuki R, Liu G (2017) Bleaching in the Ryukyu Islands in 2016 and associated Degree Heating Week threshold. Galaxea J Coral Reef Stud 19:17-18. https://doi.org/10.3755/galax ea.19.1_17

Kenter JO (2018) IPBES: don't throw out the baby whilst keeping the bathwater; put people's values central, not nature's contributions. Ecosyst Services 33:40-43. https://doi.org/10.1016/j. ecoser.2018.08.002 
Kenter JO et al (2015) What are shared and social values of ecosystems? Ecol Econ 111:86-99. https://doi.org/10.1016/j.ecolecon. 2015.01.006

Kenter JO et al (2016) Shared values and deliberative valuation: future directions. Ecosyst Serv 21:358-371. https://doi.org/10.1016/j. ecoser.2016.10.006

Kumamoto K (1995) Sustainable development and living systems. Gakuyo-shobo, Tokyo (in Japanese)

Lau JD, Hicks CC, Gurney GG, Cinner JE (2019) What matters to whom and why? Understanding the importance of coastal ecosystem services in developing coastal communities. Ecosyst Serv 35:219-230. https://doi.org/10.1016/j.ecoser.2018.12.012

Lazarsfeld PF, Barton AH (1951) Qualitative measurement in the social sciences, classification, typologies, and indices. In: Lerner D, Lasswell HD (eds) The policy sciences: recent developments in scope and method. Stanford University Press, Stanford, CA, pp 180-188

Liu T, Geng L, Ye L, Zhou K (2019) "Mother Nature" enhances connectedness to nature and pro-environmental behavior. J Environ Psychol 61:37-45. https://doi.org/10.1016/j.jenvp.2018.12.003

Millennium ecosystem assessment (MA) (2005) Ecosystem and human well-being - summary for decision makers. Island Press, Washington, DC

Makino M, Hori M, Nanami A, Hori J, Tajima H (2020) Mapping the policy interventions on marine social-ecological systems: case study of Sekisei Lagoon, southwest Japan. In: Saito O, Subramanian SM, Hashimoto S, Takeuuchi K (eds) Managing Socioecological production landscapes and seascapes for sustainable communities in Asia. Springer Open, pp 11-29

Marshall NA, Park SE, Adger WN, Brown K et al (2012) Transformational capacity and the influence of place and identity. Environ Res Lett 7(3):034022. https://doi.org/10.1088/1748-9326/7/3/ 034022

Martin CL, Momtaz S, Gaston T, Moltschaniwskyj NA (2016) A systematic quantitative review of coastal and marine cultural ecosystem services: current status and future research. Mar Pol 74:25-32. https://doi.org/10.1016/j.marpol.2016.09.004

Martin Wong CW, Conti-Jerpe I, Raymundo LJ, Dingle C, Araujo G, Ponzo A, Baker DM (2019) Whale shark tourism: impacts on coral reefs in the Philippines. Environ Manag 63:282-291. https://doi.org/10.1007/s00267-018-1125-3

Martin-Ortega J, Azahara Mesa-Jurado M, Pineda-Vazquez M, Novo P (2019) Nature commodification: 'a necessary evil'? An analysis of the views of environmental professionals on ecosystem services-based approaches. Ecosyst Serv 37:100926. https:// doi.org/10.1016/j.ecoser.2019.100926

Masterson VA et al (2017) The contribution of sense of place to social-ecological systems research: a review and research agenda. Ecol Soc 22(1):49. https://doi.org/10.5751/ ES-08872-220149

Milcu AI et al (2013) Cultural ecosystem services: a literature review and prospects for future research. Ecol Soc 18(3):44. https:// doi.org/10.5751/ES-05790-180344

Ministry of Environment, Japan (2010) The Action Plan to Conserve Coral Reef Ecosystem in Japan. http://www.env.go.jp/nature/ biodic/coralreefs/pamph/pamph_full-en.pdf. Accessed $15 \mathrm{Sept}$ 2020.

Ministry of Internal Affairs and Communication, Japan (2015) Population and Households of Japan 2015 (in Japanese). http://www.stat. go.jp/data/kokusei/2015/kekka.htm. Accessed 15 Sept 2020

Morrison TH, Adger N, Barnett J, Brown K, Possingham H, Hughes T (2020) Advancing coral reef governance into the anthropocene. One Earth 2(1):64-74. https://doi.org/10.1016/j.oneear.2019.12. 014

Muradian R, Pascual U (2018) A typology of elementary forms of humannature relations: a contribution to the valuation debate. Curr Opin
Environ Sustain 35:8-14. https://doi.org/10.1016/j.cosust.2018.10. 014

Nakamatsu Y (1990) Spirits and the Village. Shinsensha, Tokyo (in Japanese)

Newman MEJ (2004) Fast algorithm for detecting community structure in networks. Phys Rev E 69(6):066133. https://doi.org/10.1103/ PhysRevE.69.066133

Newman MEJ (2010) Networks: an introduction. Oxford University Press, Oxford, UK

Nomoto K (2006) Landscapes of gods and nature. Kodansha, Tokyo (in Japanese)

Osgood CE (1959) Linguistic and content analysis. In: Pool IDS (ed) Trends in content analysis. University of Illinois Press, Urbana, IL, pp 33-88

Österblom H, Jouffray JB, Folke C, Rockström J (2017) Emergence of a global science-business initiative for ocean stewardship. Proc Nat Acad Sci USA. https://doi.org/10.1073/pnas.1704453114

Packer H, Schmidt J, Bailey M (2020) Social networks and seafood sustainability governance: exploring the relationship between social capital and the performance of fishery improvement projects. People Nat 2:797-810. https://doi.org/10.1002/pan3.10116

Pajon C (2010) Understanding the Issue of U.S. Military Bases in Okinawa. Asie. Visions, No. 29 understanding_the_issue_ of_u.s._military_bases_in_okinawa.pdf

Pascua P, McMillen H, Ticktin T, Vaughan M, Winter KB (2017) Beyond services: a process and framework to incorporate cultural, genealogical, place-based, and indigenous relationships in ecosystem service assessments. Ecosyst Serv 26:465-475. https://doi.org/10.1016/j.ecoser.2017.03.012

Pascual U et al (2017) Valuing nature's contributions to people: the IPBES approach. Curr Opin Environ Sustain 26-27:7-16. https:// doi.org/10.1016/j.cosust.2016.12.006

Pereira LM, Davies KK, den Belder E et al (2020) Developing multiscale and integrative nature-people scenarios using the Nature Futures Framework. People Nat. https://doi.org/10.1002/pan3. 10146

Pert PL et al (2015) Mapping cultural ecosystem services with rainforest aboriginal peoples: integrating biocultural diversity, governance and social variation. Ecosyst Serv 13:41-56. https://doi.org/ 10.1016/j.ecoser.2014.10.012

Pressey RL, Weeks R, Gurney GG (2017) From displacement activities to evidence-informed decisions in conservation. Biol Conserv 212(A):337-348. https://doi.org/10.1016/j.biocon.2017.06.009

R Core Team (2019) R: A language and environment for statistical computing. R Foundation for Statistical Computing, Vienna, Austria. https://www.R-project.org/. Accessed 15 Sept 2020

Rerichardt J, Bornholdt S (2004) Detecting fuzzy community structures in complex networks with a Potts model. Phys Rev Lett 93:218701

Saporta S, Sebeok TA (1959) Linguistic and content analysis. In: Pool IDS (ed) Trends in content analysis. University of Illinois Press, Urbana, IL, pp 131-150

Sato M, Nanami A, Bayne CJ, Makino M, Hori M (2020) Changes in the potential stocks of coral reef ecosystem services following coral bleaching in Sekisei Lagoon, southern Japan: implications for the future under global warming. Sustain Sci 15(3):863-883. https://doi.org/10.1007/s11625-019-00778-6

Sugimoto A (2016) Fish as a 'bridge' connecting migrant fishers with the local community: findings from Okinawa, Japan. Marit Stud 15:5. https://doi.org/10.1186/s40152-016-0046-0

Sugino H, Hayashi N, Sekiguchi T, Terada Y (2017) Understanding the image of sea for japanese people by free association questionnaire. J Coast Zone Stud 30(1):29-40

Tabeta M (1990) Economics of commons. Gakuyo-shobo, Tokyo (in Japanese) 
Tada O (2004) Emergence of the Okinawan Image: cultural studies of the blue ocean. Toyokeizai shimpo-sha, Tokyo (in Japanese)

Tada O (2008) Travelling the Okinawan Image. Chuokoron-shinsha, Tokyo (in Japanese)

Tam KP, Lee SL, Chao MM (2013) Saving Mr. Nature: anthropomorphism enhances connectedness to and protectiveness toward nature. J Exp Soc Psychol 49:514-521. https://doi.org/10.1016/j. jesp.2013.02.001

TEEB (2010) The economics of ecosystems and biodiversity: Ecological and economic foundation. Earthscan, Cambridge

UK National Ecosystem Assessment (2011) The UK National Ecosystem Assessment: synthesis of the key findings. UNEP-WCMC, Cambridge

UK National Ecosystem Assessment Follow-on (2014) The UK National Ecosystem Assessment: synthesis of the key findings. UNEP-WCMC, LWEC, UK

Urquhart J, Acott T (2014) A sense of place in cultural ecosystem services: the case of Cornish fishing communities. Soc Nat Resour 27(1):3-19. https://doi.org/10.1080/08941920.2013.820811

van Putten IE et al (2018) A framework for incorporating sense of place into the management of marine systems. Ecol Soc 23(4):4. https://doi.org/10.5751/ES-10504-230404

Wakita K (2018) Implementation status of measures on integrated coastal management provided in basic plan on ocean policy. Jpn J Coast Zone Stud 30(4):125-134 (in Japanese)

Wakita K, Yagi N (2013) Evaluating integrated coastal management policy in Japan: why the Guideline 2000 has not been implemented. Ocean Coast Manag 84:97-106. https://doi.org/10. 1016/j.ocecoaman.2013.07.012
Wasserman S, Faust K (1994) Structural analysis in the social sciences. Soc Netw Anal. https://doi.org/10.1017/CBO9780511 815478Newman

Watsuji T (1979) A climate. Iwanami-shoten, Tokyo (in Japanese)

Williams B (2013) The YIMBY phenomenon in Henoko, Okinawa: compensation politics and grassroots democracy in a base community. Asian Surv 53(5):958-978. https://doi.org/10.1525/AS. 2013.53.5.958

Wong CM, Conti-Jerpe I, Raymundo LJ, Dingle C, Araujo G, Ponzo A, Baker DM (2019) Whale shark tourism: impacts on coral reefs in the Philippines. Environ manag 63(2):282-91.https://doi.org/ 10.1007/s00267-018-1125-3

Yamano H, Satake K, Inoue T, Kadoya T, Hayashi S, Kinjo K, Nakajima D, Oguma H, Ishiguro S, Okagawa A, Suga S, Horie T, Nohara K, Fukayama N, Hibiki A (2015) An integrated approach to tropical and subtropical island conservation. J Ecol Environ 38(2):271-279. https://doi.org/10.5141/ecoenv.2015.028

Yamashita H (2020) Living together with seawalls: risks and reflexive modernization in Japan. Environ Sociol 6(2):166-181. https:// doi.org/10.1080/23251042.2019.1709680

Publisher's Note Springer Nature remains neutral with regard to jurisdictional claims in published maps and institutional affiliations. 